\title{
Optimization of Headspace Solid-Phase Microextraction Conditions for the Identification of Phytophthora cinnamomi Rands
}

Rui Qiu, College of Natural Resources and Environment, Northwest A\&F University, Yangling, Shaanxi 712100, China; Cooperative Research Centre for National Plant Biosecurity, Bruce, ACT 2617 Australia; and School of Veterinary and Life Sciences, Murdoch University, Murdoch, WA, 6150 Australia; Dong Qu, College of Natural Resources and Environment, Northwest A\&F University, Yangling; Giles E. St. J. Hardy, Centre for Phytophthora Science and Management (CPSM), School of Veterinary and Life Sciences, Murdoch University, Murdoch, WA, 6150 Australia; and Cooperative Research Centre for National Plant Biosecurity, Bruce; Robert Trengove and Manjree Agarwal, Cooperative Research Centre for National Plant Biosecurity, Bruce; and School of Veterinary and Life Sciences, Murdoch University, Murdoch; and Yonglin Ren, Cooperative Research Centre for National Plant Biosecurity, Bruce; School of Veterinary and Life Sciences, Murdoch University, Murdoch; and Department of Agriculture and Food, Western Australia, Perth, WA 6151 Australia

\begin{abstract}
Qiu, R., Qu, D., Hardy, G. E. St. J., Trengove, R., Agarwal, M., and Ren, Y. 2014. Optimization of headspace solid-phase microextraction conditions for the identification of Phytophthora cinnamomi Rands. Plant Dis. 98:1088-1098.

A robust technique was developed to identify Phytophthora cinnamomi using headspace solid-phase microextraction (HS-SPME) combined with gas chromatography (GC) coupled to a flame ionization detector (FID) for analyzing volatile organic compounds (VOCs). Six fiber types were evaluated and results indicated that the three-phase fiber $50 / 30 \mu \mathrm{m}$ divinylbenzene/carboxen/polydimethylsiloxane (DVB/CAR/ PDMS) had the highest extraction efficiency for both polar and nonpolar GC columns. The maximum extraction efficiency (equilibrium absorption) was achieved $16 \mathrm{~h}$ after fiber exposure in the HS. Absorbed compounds on the fiber were completely desorbed in the GC injector after $5 \mathrm{~min}$ at $250^{\circ} \mathrm{C}$. Compared with the nonpolar column, the polar column showed optimum separation of VOCs released from P. cinnamomi. Under the optimized HS-SPME and GC/FID conditions, lower detection limits for the four external standards was found to be between 1.57 to $27.36 \mathrm{ng} /$ liter. Relative standard deviations $<9.010 \%$ showed that the method is precise and reliable. The method also

showed good linearity for the concentration range that was analyzed using four standards, with regression coefficients between 0.989 and 0.995 , and the sensitivity of the method was $10^{4}$ times greater than that of the conventional HS method. In this study, the VOC profiles of six Phytophthora spp. and one Pythium sp. were characterized by the optimized HS-SPME-GC method. The combination of the VOCs creates a unique pattern for each pathogen; the chromatograms of different isolates of $P$. cinnamomi were the same and the specific VOC pattern of P. cinnamomi remained consistently independent of the growth medium used. The chromatograms and morphological studies showed that $P$. cinnamomi released specific VOCs at different stages of colony development. Using the optimized HS-SPME GC method, identification of $P$. cinnamomi from 15 in vivo diseased soil samples was as high as $100 \%$. Results from this study demonstrate the feasibility of this method for identifying $P$. cinnamomi and the potential use of this method for physiological studies on $P$. cinnamomi.
\end{abstract}

Phytophthora cinnamomi is a microscopic soilborne plant pathogen that can invade and destroy the root systems of susceptible native and introduced plant species. It is the most widely distributed Phytophthora sp., with over 3,000 host species (15). The most significant crop losses due to $P$. cinnamomi root rot occur in avocado and chestnut. $P$. cinnamomi has been associated with the widespread mortality of oak trees and is the cause of one of the most extensive epidemics in natural ecosystems in the southwest area of Western Australia $(4,26)$. A range of fauna are affected by $P$. cinnamomi-induced changes to vegetation, including small mammals, reptiles, birds, and invertebrates (12,32). P. cinnamomi, with its enormous host range spanning many genera of rare and endemic plants, has been named by the Australian Government as one of the 15 "Key Threatening Processes" endangering ecosystems and ecological processes in Australia (9).

Developing robust, timely, and sensitive diagnostic methods for $P$. cinnamomi infection is very important to prevent its introduction and spread. Traditionally, identification of Phytophthora spp. start

Corresponding author: Y. Ren, E-mail: y.ren@ murdoch.edu.au

R. Qiu, G. Hardy, M. Agarwal, and Y. Ren contributed equally to this work.

Accepted for publication 4 February 2014.

http://dx.doi.org/10.1094/PDIS-12-13-1258-RE

(C) 2014 The American Phytopathological Society with isolation, and the main method to isolate Phytophthora spp from symptomatic plants is by plating necrotic material onto Phytophthora-selective agar or baiting diseased tissues and rhizosphere soil with fresh young leaf material as "baits"; necrotic lesions from the baits are then plated onto selective agar (10). This process, though effective, is slow and requires experienced personnel to identify the pathogen based on morphological characteristics. Electrophoretic patterns of isozymes and serological methods based on use of antibodies are only useful for $P$. cinnamomi identification from pure cultures and these methods are slow and expensive, have limited usefulness, are not necessarily species-specific, and need to be confirmed by morphological or molecular methods (6). More recently, a variety of molecular techniques have been used for the identification of P. cinnamomi and other Phytophthora spp. Conventional polymerase chain reaction (PCR) identification is based on amplification and pyrosequencing (30); fingerprinting techniques that include restriction fragment length polymorphism of the internal transcribed spacer region $(5,21)$, random amplified polymorphic DNAs (20), and amplified fragment length polymorphisms (8) with nested PCR are all based on conventional PCR and are sensitive and simple but require an agarose or acrylamide gel electrophoresis to visualize the amplified bands, and increase the time required for sample analysis. Real-time PCR eliminates the requirement for post-amplification amplicon detection procedures, including gel electrophoresis, and avoids the problem of cross contamination of reactions that is inherent in nested PCR (11). The technique can also be implemented in the field by using portable real-time PCR machines. Also, without the addition of ethidium 
bromide, health risks for operators and environmental contamination are reduced $(29,31)$. However, it is restricted by the number of fluorescent probes and, in some cases, the primers in multiplex reactions interfere with each other, resulting in a lower sensitivity of detection or the generation of additional amplicons $(18,28)$. Therefore, there is an important need to develop other robust, rapid, highly specific, and cost effective diagnostic methods for the identification of Phytophthora spp. from plant and soil material.

A novel nondestructive and noninvasive extraction method (no preprocessing of the sample before separation is required, ensuring sample integrity) for the detection of specific microbial-emitted volatile organic compounds (VOCs) has been developed to discriminate microbes in soil, food, feeds, and grains $(17,23,25)$, and a number of studies have shown that VOCs released by microbes change with the different stages of their growth $(13,22,34)$. Although several marker volatiles of $P$. infestans have been identified $(7,19)$ and applied to detect $P$. infestans infection, specific volatiles have not been discriminated for the identification of $P$. cinnamomi. Solid-phase microextraction (SPME) is a new sample enrichment and solvent-free extraction technique which integrates sampling, extraction, concentration, and sample introduction in a single step. Since its development in 1989 by Arthur and Pawliszyn (2), its applications have dramatically increased. The SPME in combination with headspace (HS) analysis by gas chromatography (GC; a very common laboratory analytical instrument) is a convenient alternative method for the analysis of VOCs.

The objectives of this article were to prove the feasibility of using VOCs together with HS-SPME as an identification tool and to establish optimal HS-SPME and GC conditions for the identification of P. cinnamomi.

\section{Materials and Methods}

Reagents. BBL agar, grade A (reference 212304), used for preparation of V8 juice agar (V8A), and Difco potato dextrose agar (PDA; reference 213400) were purchased from Becton, Dickinson and Company. Organic solvents, including methanol, ethanol, and ethyl formate, were purchased from MERK (high-performance liquid chromatography [HPLC] grade); hexane was purchased from Fisher Scientific (catalog number H306, HPLC grade).

Equipment and apparatus. Erlenmeyer flasks $(100 \mathrm{ml}$; Quickfit, catalog number QFY-372-P) were used for preparation of samples. Each flask was fitted with an adapter (Quickfit, part number AQST53/13) equipped with a septum (Grace, catalog number 6518). Glass bottles of $250 \mathrm{ml}$ (Alltech, catalog number 9535), each fitted with a Mininert valve and septum (Alltech, catalog number 95326) were used for preparation of gas standards. An Olympus BX51 microscope (serial number 3M08876) was used to study the morphology of P. cinnamomi.

Six different types of SPME fiber were compared to evaluate their effectiveness on the extraction of VOCs produced by $P$. cinnamomi. The tested SPME fibers were $7 \mu \mathrm{m}$ polydimethylsiloxane (PDMS) fiber (Sigma-Aldrich Australia, catalog number 57307), $100 \mu \mathrm{m}$ PDMS fiber (Sigma-Aldrich Australia, catalog number 57300-U), 50/30 $\mu \mathrm{m}$ divinylbenzene/carboxen (DVB/CAR)/PDMS fiber (Sigma-Aldrich Australia, catalog number 57348-U), $65 \mu \mathrm{m}$ PDMS/DVB fiber (Sigma-Aldrich Australia, catalog number 57310-U), $85 \mu \mathrm{m}$ polyacrylate (PA) fiber (Sigma-Aldrich Australia, catalog number 57307), and $85 \mu \mathrm{m}$ CAR/PDMS fiber (SigmaAldrich Australia, catalog number 57334-U). Prior to use, the fibers were conditioned according to the manufacturers' recommen- dations, and cleaned between each extraction by exposing the fibers into the $\mathrm{GC}$ injection port for $15 \mathrm{~min}$ at $250^{\circ} \mathrm{C}$ for the 100 $\mu \mathrm{m}$ PDMS and PDMS/DVB fibers, and $15 \mathrm{~min}$ at $260^{\circ} \mathrm{C}$ for the other four fibers.

Analysis of VOCs was performed on an Agilent 6890 series (serial number US00021731) gas chromatograph coupled to a flame ionization detector (FID). Injector and detector temperatures were $250^{\circ} \mathrm{C}$, except when the injector temperature was varied to assess its effect on desorption of VOCs from the fiber. In order to get the optimal blueprint of P. cinnamomi, both polar and nonpolar columns were used for the separation of VOCs. Separation was achieved on a ZB-WAX plus capillary polar column $(30 \mathrm{~m}$ by 0.25 $\mathrm{mm}$ ID, film thickness $0.25 \mu \mathrm{m}$; Zebron, part number 7HG-G01311) and an Rxi-5ms nonpolar column $(30 \mathrm{~m}$ by $0.25 \mathrm{~mm}$, film thickness $0.25 \mu \mathrm{m}$; Crossbond 5\% diphenyl and 95\% dimethyl polydiloxane; RESTEK, catalog number 13423) separately. Hydrogen was used as carrier gas at a flow rate of $1.0 \mathrm{ml} \mathrm{min}^{-1}$. The GC column temperature was programmed to hold temperature at $45^{\circ} \mathrm{C}$ for $5 \mathrm{~min}$, then increased by $5^{\circ} \mathrm{C} \mathrm{min}^{-1}$ to $250^{\circ} \mathrm{C}$ and held for 5 min, and the GC-FID instrument was operated under the splitless mode.

Data were collected with GC online software and analyzed by ChemStation instrument offline software and Microsoft Excel 2007.

Phytophthora and Pythium spp., P. cinnamomi isolates, VOC detection, and microscopic observation. Six Phytophthora spp., including five isolates of $P$. cinnamomi (Table 1), $P$. niederhauserii (PAB 13-29), P. elongata (VHS 13784), P. humicola (VHS 25241), $P$. inundata (VHS 25170), and P. multivora (VHS 14926); and one Pythium sp., Pythium dissotocum (SA370), were obtained from the Centre for Phytophthora Science and Management (CPSM), Murdoch University, Australia.

Phytophthora and Pythium spp. were grown on 10\% V8A in petri dishes in the dark at $24 \pm 1{ }^{\circ} \mathrm{C}$ and subcultured every 10 days via mycelial mass transfer. A single 4-mm-diameter plug from the edge of the 5-day-old pathogen cultures was used as inoculum and transferred to a 100-ml Erlenmeyer flask containing $50 \mathrm{ml}$ of V8A. Inocula of the five Phytophthora cinnamomi isolates were also transferred to $50 \mathrm{ml}$ of PDA. All the cultures were incubated at 24 $\pm 1^{\circ} \mathrm{C}$ in the dark for 6 days and VOC detection was conducted.

A single 4-mm-diameter agar disc colonized by a 5-day-old $P$. cinnamomi isolate (MP94.48) colony grown on V8A was transferred to a 100-ml Erlenmeyer flask containing $50 \mathrm{ml}$ of V8A, the culture was incubated for 15 days at $24 \pm 1^{\circ} \mathrm{C}$ in the dark, and morphological observation and VOC detection were conducted daily. Each treatment combination was replicated three times and each experiment was repeated more than three times.

Inoculation. Seedlings of Lupinus angustifolius 'Danja', the commonly used bait plant for P. cinnamomi, were used as the susceptible host plant for this study. Seed of L. angustifolius Danja were surface sterilized by soaking them with $70 \%$ ethanol for 2 min followed by immersion in $50 \%$ bleach solution $(6.25 \%$ available chlorine) for $5 \mathrm{~min}$, and then rinsed five times in sterile distilled water. The sterilized seed were germinated on sterilized filter paper, which was premoistened with sterilized distilled water at 24 $\pm 1^{\circ} \mathrm{C}$ in the dark for 2 days.

Lupin sample inoculation. Three uniform 2-day-old lupin seedlings were transferred to a 100-ml Erlenmeyer flask with $1 \mathrm{ml}$ of sterilized distilled water and grown for a further day. A single 4$\mathrm{mm}$ plug from the edge of the 5-day-old P. cinnamomi MP 94.48

Table 1. Phytophthora cinnamomi isolates used in this study

\begin{tabular}{lcclcl}
\hline Isolate code & Type & GenBank number & Country & Host & Year \\
MP 94.48 & A2 & JX113294 & Australia & Eucalyptus marginata & 1994 \\
W4 & A2 & JX113312 & Australia & Chamaescilla corymbosa & 2011 \\
W15 & A2 & JX113308 & Australia & Stylidium diuroides & 2011 \\
MP75 & A1 & NA & Australia & Eucalyptus marginata & ND \\
DCE 25 & A1 5 & JX454790 & Australia & Hypocalymma angustifolia & 1969 \\
\hline
\end{tabular}

${ }^{\mathrm{a}} \mathrm{NA}=$ not applicable, and $\mathrm{ND}=$ no data. 
culture was used as inoculum, placed on the tip of the root, and kept in dark at $24 \pm 1^{\circ} \mathrm{C}$ for 3 days to allow lesions to develop.

Soil sample inoculation. Washed white river sand was purchased from Sand and Soil. To ensure that the seedlings were grown at "container capacity" conditions for optimum growth, $13.6 \mathrm{ml}$ of $10 \%$ V8 broth was added to a 100-ml Erlenmeyer flask containing $100 \mathrm{~g}$ of sand and sterilized. Three lupin seedlings were transferred to the sterilized sand and grown for a further 2 days. Six 4-mmdiameter agar plugs colonized with 5-day-old $P$. cinnamomi MP94.48 were transferred aseptically to the middle of the sand layer in each flask; controls consisted of six similar-sized V8A plugs that had not been colonized by the pathogen. All the treatments were then incubated for 6 days at $24 \pm 1{ }^{\circ} \mathrm{C}$ in the dark, at which time VOC detection was conducted.

Optimization of HS-SPME. According to Risticevic et al. (24), a typical SPME method can be optimized for many aspects and, based on the objectives of the current study, the following SPME parameters were evaluated and optimized: fiber coating, extraction time, and desorption conditions. While optimizing one condition, all other conditions were kept constant. Some parameters such as the VOC collection chamber (100-ml Erlenmeyer flask with an adapter and a septum), $250^{\circ} \mathrm{C}$ GC detector temperature, and the fiber extraction temperature of $24 \pm 1^{\circ} \mathrm{C}$ were kept constant throughout the experiment.

The sensitivity of an HS-SPME in combination with GC relies on optimized conditions. The first step followed in this study was to optimize the HS-SPME method to maximize the range and amount of VOCs extracted. An optimized chromatographic separa- tion begins with the column: a nonpolar column is better for analyses of nonpolar compounds while polar columns most effectively separate polar compounds. In order to get the most reliable information, both polar and nonpolar columns and polar and nonpolar fibers were used in this study.

Selection of fiber. The six fiber types were exposed in the HS of a $100-\mathrm{ml}$ Erlenmeyer flask over the 5-day-old P. cinnamomi MP 94.48 colony grown on V8A and V8A alone (as control) for $3 \mathrm{~h}$ of exposure and 5 min of desorption in the GC injector.

Determination of exposure time of fiber extraction. The selected fiber was exposed to the HS of the 100-ml flasks containing a 5day-old P. cinnamomi MP 94.48 colony grown on $50 \mathrm{ml}$ of V8A and V8A alone for a time periods of 3 to $24 \mathrm{~h}$ for both the polar column and nonpolar column. After exposure, the fiber was retrieved and injected into the heated GC injection port $\left(250^{\circ} \mathrm{C}\right)$ and desorbed for $5 \mathrm{~min}$. For each treatment and time combination, there were three replicate flasks and three replicate extractions per flask.

Determination of desorption temperature and time. The selected fiber $(50 / 30 \mu \mathrm{m}$ DVB/CAR/PDMS) and the optimized fiber extraction time $(16 \mathrm{~h})$ were used to optimize the GC injector temperature and desorption time. Determination of the optimal injector temperature was conducted on both the polar and nonpolar columns. The fiber was desorbed in the GC injection port at different injector temperatures (from 200 to $270^{\circ} \mathrm{C} ; 270^{\circ} \mathrm{C}$ is the highest temperature the fiber can withstand) for $5 \mathrm{~min}$. The fiber was desorbed for different desorption times $(1,3,5$, and $7 \mathrm{~min})$ at the selected optimal injector temperature to determine the optimal desorption time.

Table 2. Soil samples used to detect the presence of Phytophthora cinnamomi in this study

\begin{tabular}{llc}
\hline Sample code & \multicolumn{1}{c}{ Host $^{\mathrm{a}}$} & \multicolumn{1}{c}{ Location } \\
\hline 716 & Banksia attenuata & $30^{\circ} 38^{\prime} 02 \cdot 6^{\prime \prime} \mathrm{S}, 115^{\circ} 25^{\prime} 45 \cdot 3^{\prime \prime} \mathrm{E}$ \\
717 & Banksia menziesii & $30^{\circ} 38^{\prime} 02 \cdot 3^{\prime \prime} \mathrm{S}, 115^{\circ} 25^{\prime} 45 \cdot 5^{\prime \prime} \mathrm{E}$ \\
722 & Trachymene sp.; Ericaceae (unid.) & $30^{\circ} 37^{\prime} 52 \cdot 8^{\prime \prime} \mathrm{S}, 115^{\circ} 25^{\prime} 58 \cdot 3^{\prime \prime} \mathrm{E}$ \\
T2+4 & Hibbertia sp. & $30^{\circ} 38^{\prime} 02 \cdot 7^{\prime \prime} \mathrm{S}, 115^{\circ} 25^{\prime} 48 \cdot 2^{\prime \prime} \mathrm{E}$ \\
T2+6 & Banksia attenuata; Myrtaceae (unid.) & $\ldots$ \\
T3+4 & Hibbertia sp.; Melaleuca sp. & $30^{\circ} 37^{\prime} 59 \cdot 2^{\prime \prime} \mathrm{S}, 115^{\circ} 25^{\prime} 47 \cdot 8^{\prime \prime} \mathrm{E}$ \\
T3+6 & Banksia attenuata, Conostephium sp., Ericaceae (unid.) & $\ldots$ \\
T3+8 & Ericaceae (unid.); Banksia sp. (unid.) roots & $\ldots$ \\
T6-4 & Ericaceae (unid.) & $30^{\circ} 38^{\prime} 02 \cdot 7^{\prime \prime} \mathrm{S}, 115^{\circ} 25^{\prime} 45 \cdot 6^{\prime \prime} \mathrm{E}$ \\
MU22-1 & Calytrix sp.; Banksia sp. (unid) roots & $32^{\circ} 04^{\prime} 34^{\prime \prime} \mathrm{S}, 115^{\circ} 49^{\prime} 56 \cdot 4^{\prime \prime} \mathrm{E}$ \\
MU22-2 & Hibbertia sp.; Banksia (unid.) roots & $\ldots$ \\
MU22-3 & Brachyloma preissii & $\ldots$ \\
MU22-4 & Banksia sp. (unid.) roots and soil & $\ldots$ \\
MU22-5 & Brachyloma preissii & $\ldots$ \\
MU04 & Stirlingia latifolia & $32^{\circ} 04^{\prime} 28 \cdot 5^{\prime \prime} \mathrm{S}, 115^{\circ} 50^{\prime} 32 \cdot 4^{\prime \prime} \mathrm{E}$ \\
\hline
\end{tabular}

${ }^{\text {a }}$ Unid. = unidentified family or genus.

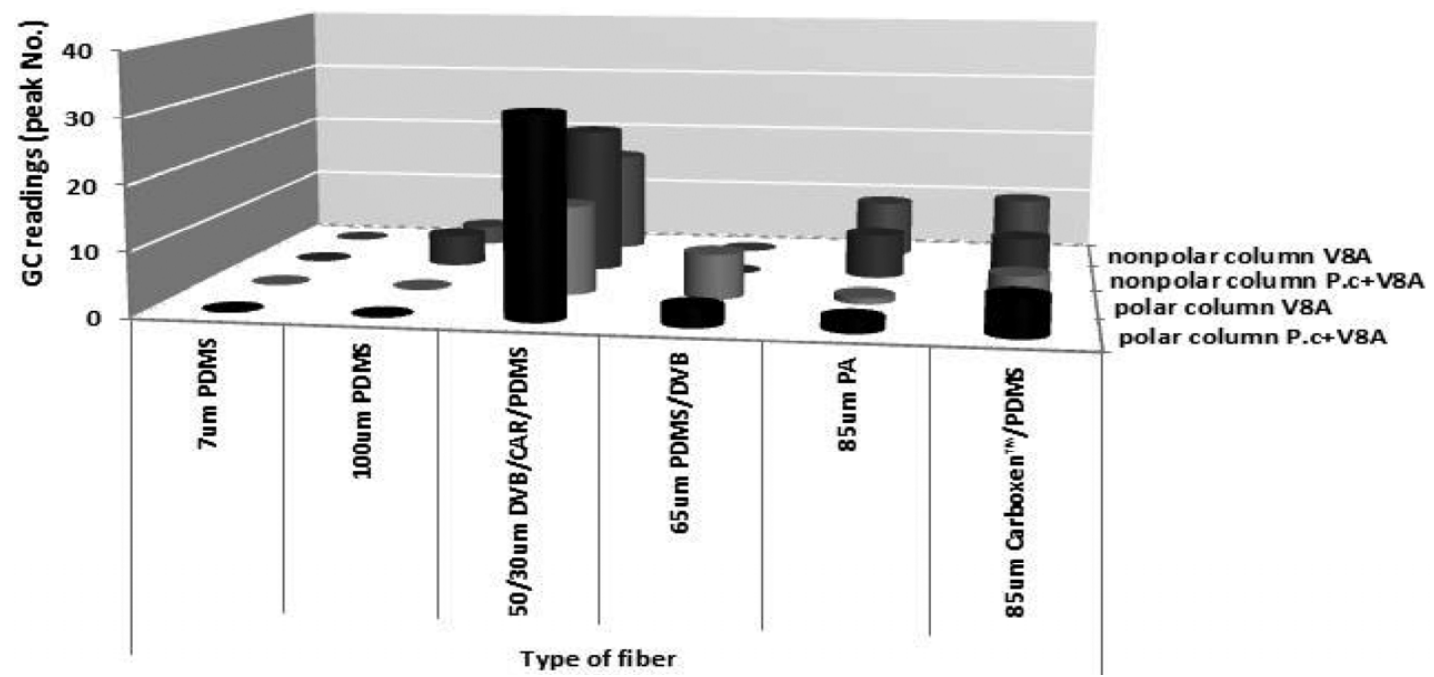

Fig. 1. Peaks produced by Phytophthora cinnamomi growing on V8 juice agar and V8 juice agar alone extracted by six different fiber types that were separated by a polar column (ZB-WAX plus) and a nonpolar column (Rxi-5ms). 
Selection of GC column. The separation efficiency of the polar and nonpolar columns was evaluated with the optimized threephase fiber at the optimal time of extraction and time and temperature of desorption.

Determination of the limit of detection for the HS-SPME coupled to GC-FID method. The limit of detection (LOD) was evaluated with hexane, methanol, ethanol, and ethyl formate as external standards. For preparation of the standards, the appropriate volumes of each standard were added into a sealed $250-\mathrm{ml}$ bottle. After $5 \mathrm{~min}$ of extraction with the fiber $50 / 30 \mu \mathrm{m} \mathrm{DVB/CAR/}$ PDMS at room temperature $\left(24 \pm 1^{\circ} \mathrm{C}\right)$, the fiber was injected into the gas chromatograph at the injector temperature of $250^{\circ} \mathrm{C}$.

All samples were duplicated and each sample were analyzed as triplicate injections.

Identification of $P$. cinnamomi from forest soil samples using the optimized HS-SPME GC method. Fifteen soil samples naturally infected by $P$. cinnamomi were collected from diseased, susceptible plant rhizosphere from Murdoch University campus and sites south of Perth (Table 2). The youngest fully expanded oak (Quercus suber) leaves (Kings Park, WA) were used as the baits for $P$. cinnamomi. All the soil samples were separated into two groups; one group was used for HS-SPME GC analysis and the other group used for baiting.

Soil samples for baiting were transferred into 1-liter takeaway containers and filled with deionized water. The fresh oak leaves were then floated on the water surface. These baits were checked every $24 \mathrm{~h}$ for 10 days, and any leaves that developed water-soaked lesions were removed with forceps and placed into a 100-ml Erlenmeyer flask in preparation for HS-SPME extraction. In addition to the above, some of the soaked baits were dried on paper towels; then, small sections approximately $5 \mathrm{~mm}$ square were excised with a sterile scalpel and plated onto Phytophthora selective medium (NARPH; 16) and the plates were incubated at $24 \pm 1{ }^{\circ} \mathrm{C}$ in the dark. The plates were checked daily under the compound microscope to determine whether $P$. cinnamomi had been successfully isolated from the soil. Baiting water $(50 \mathrm{ml})$ for each soil sample was filled into a 100-ml Erlenmeyer flask in preparation for HSSPME extraction also.

In addition to baiting, $50 \mathrm{~g}$ of each soil sample was placed directly into a 100-ml Erlenmeyer flask for HS-SPME extraction.

The optimized HS-SPME GC method was used for analyzing the VOCs from fresh soil, baiting water, and baits.

Statistical analysis. The variations (standard errors of the mean) of VOCs and external standards concentrations, the triplicate samples, and the triplicate injections in comparison with average readings were analyzed by Microsoft Excel 2007.

\section{Results}

Selection of fiber and determination of extraction time. The extraction efficiency of the six different commercially available SPME fibers ( 7 and $100 \mu \mathrm{m}$ PDMS, DVB/CAR/PDMS, PDMS/DVB, PA, and CAR/PDMS) was evaluated by comparing
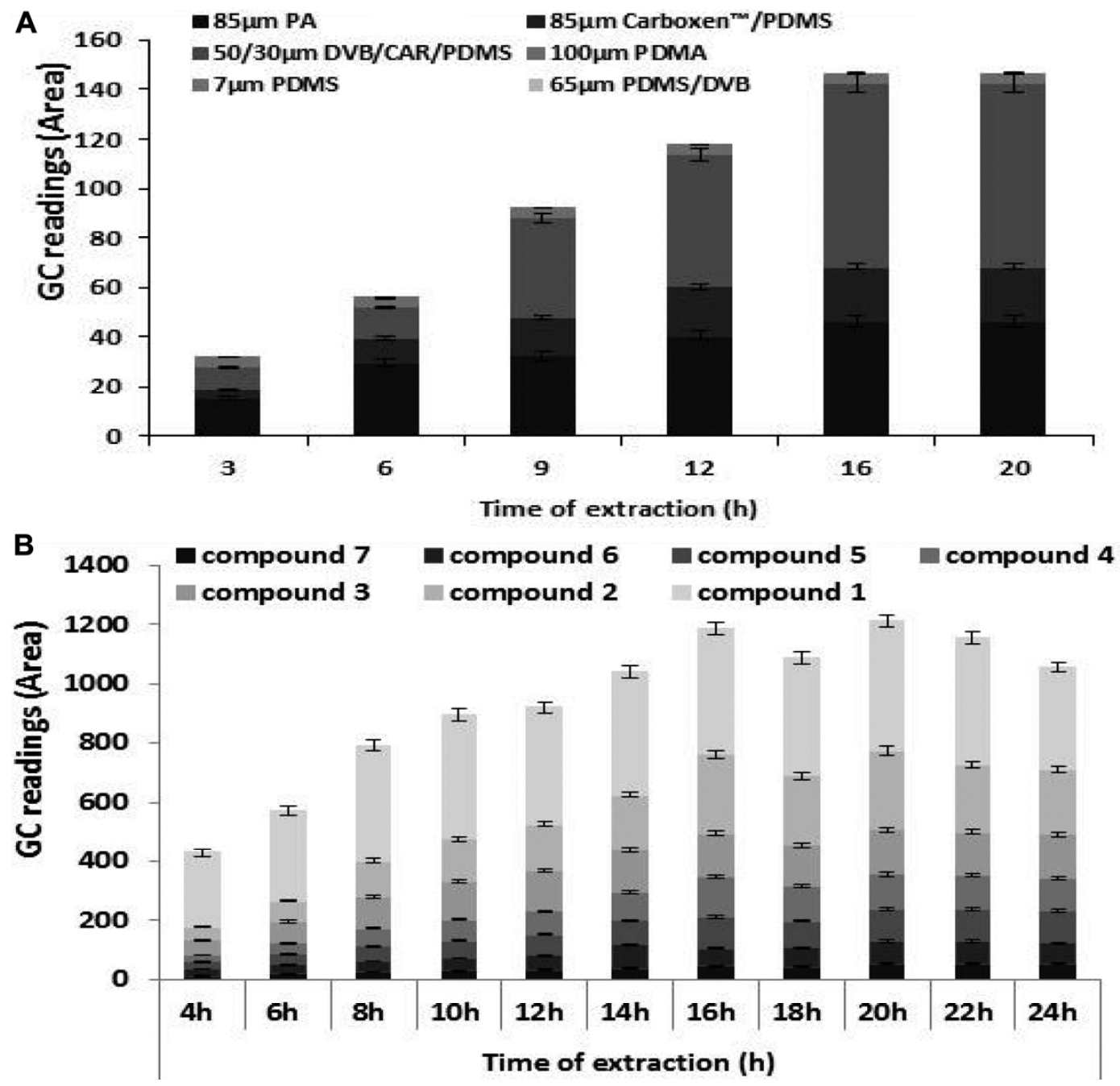

Fig. 2. A, Effects of extraction time with different fibers on the extraction efficacy of the total compounds identified from Phytophthora cinnamomi + V8 juice agar at $3,6,9,12$, 16 , and $20 \mathrm{~h}$ for the nonpolar column (Rxi-5ms); B, effects of extraction time with the 50/30 $\mu \mathrm{m}$ divinylbenzene/carboxen/polydimethylsiloxane (DVB/CAR/PDMS) fiber on the extraction efficiency of seven analytes of interest (>85\% of total identified volatile organic compounds) at $4,6,8,10,12,14,16,18,20,22$, and $24 \mathrm{~h}$ for the polar column $(\mathrm{ZB}$ WAX plus). Bars represent standard errors of mean $(n=3)$. 
the peak numbers of the compounds from P. cinnamomi $+\mathrm{V} 8 \mathrm{~A}$ and V8A alone treatments under the same extraction, desorption, and GC conditions.

After separation of VOCs desorbed from different fibers on both polar and nonpolar columns, the results showed that the threephase fiber $(50 / 30 \mu \mathrm{m}$ DVB/CAR/PDMS fiber) had the highest extraction efficiency (Fig. 1). The GC response of fiber $50 / 30 \mu \mathrm{m}$ DVB/CAR/PDMS after $16 \mathrm{~h}$ of extraction was more than two times that of fiber $85 \mu \mathrm{m}$ PA and four times that of fiber $85 \mu \mathrm{m}$ CAR/PDMS when separated on the nonpolar column (Fig. 2A), and trapped a wider range of VOCs that separated on both the polar and nonpolar columns (Fig. 1). There were no VOCs extracted with the $7 \mu \mathrm{m}$ PDMS fibers because no compounds separated from both polar and nonpolar columns (Figs. 1 and 2A).

Therefore, the three-phase fiber was selected as the appropriate fiber to optimize the other parameters. For determination of extraction time, the selected three-phase fiber was exposed in the HS of the flask for different times ( 3 to $24 \mathrm{~h}$ ). The levels of desorbed compounds increased with increasing extraction time until $16 \mathrm{~h}$ on the nonpolar column (Fig. 2A) and polar column (Fig. 2B), when equilibrium was achieved.

Evaluation of GC injector (fiber desorption) temperature and desorption time. The effect of the GC injector temperature was evaluated with the selected 50/30 $\mu \mathrm{m}$ DVB/CAR/PDMS fiber at GC inlet temperatures of 200 to $270^{\circ} \mathrm{C}$ under the HS fiber extraction time of $16 \mathrm{~h}$ over P. cinnamomi $+\mathrm{V} 8 \mathrm{~A}$ and V8A alone. The results indicated that the total area of desorbed compounds detected increased with increasing injector temperature for both the polar and nonpolar columns, and the maximum desorption from the fiber was obtained at $250^{\circ} \mathrm{C}$ (Fig. 3A). The total desorbed compounds produced decreased when the temperature was greater than $250^{\circ} \mathrm{C}$.

The various desorption times had a significant effect on GC response of $P$. cinnamomi $+\mathrm{V} 8 \mathrm{~A}$ and V8A alone. The total area of desorbed VOCs increased with an extension of desorption time from 1 to $5 \mathrm{~min}$ and then reached equilibrium at $5 \mathrm{~min}$; the GC response remained constant after a desorption time of $5 \mathrm{~min}$, which was determined as the optimum (Fig. 3B).

Selection of column. The three-phase fiber was exposed in the HS over a 6-day-old $P$. cinnamomi + V8A colony for $16 \mathrm{~h}$ and separated on both polar and nonpolar columns under the optimized HS-SPME GC conditions. The VOCs of the samples had better separation and were more sensitive for most separated VOCs on the polar column than the nonpolar column, and a broader range of compounds was captured on the polar column (Fig. 4). Therefore, the polar column was selected for the subsequent studies.

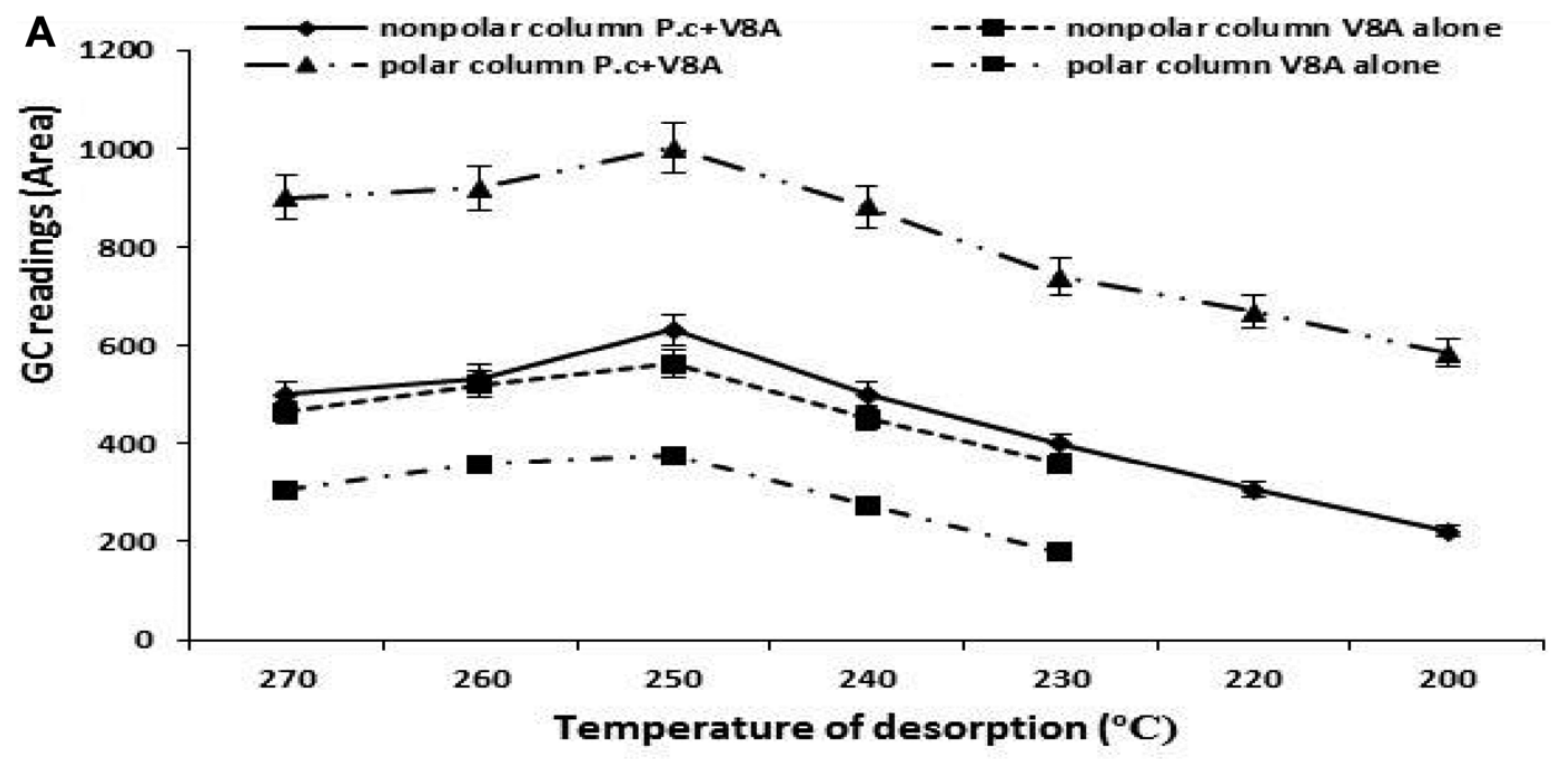

B

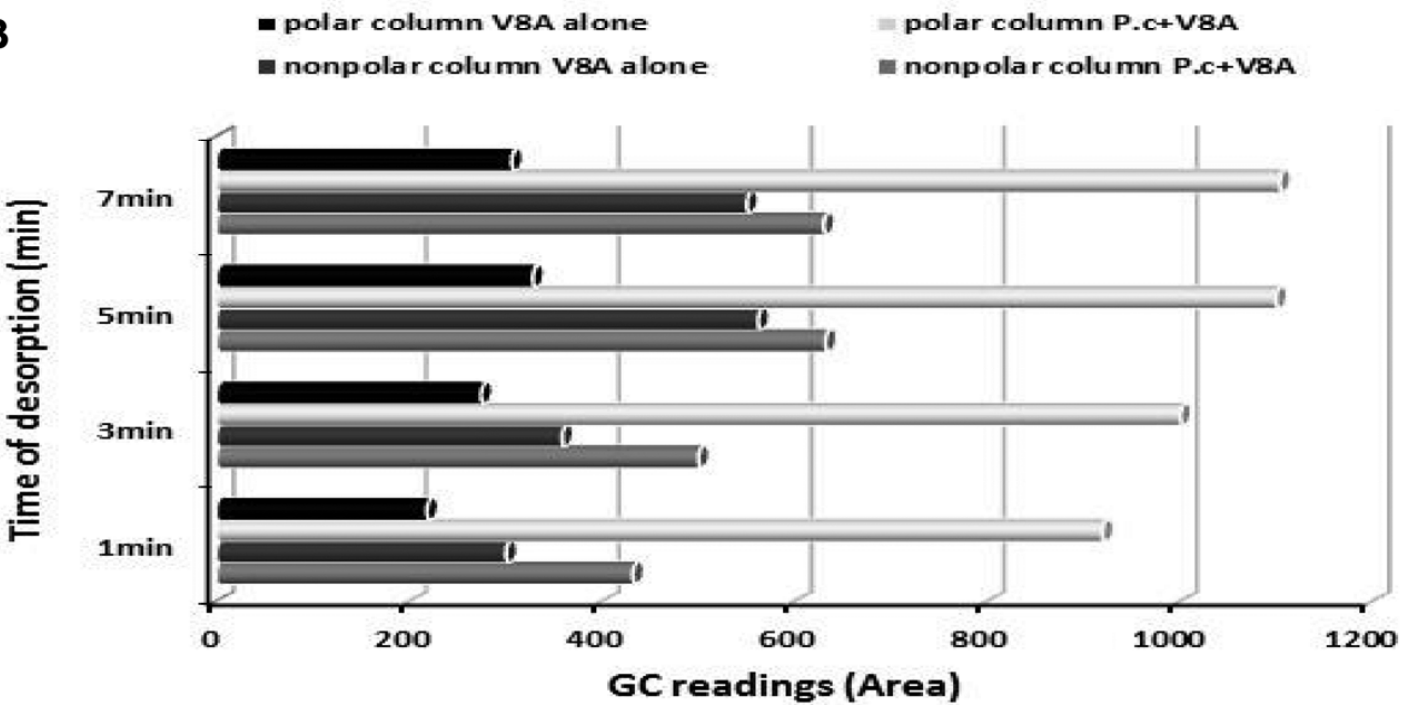

Fig. 3. A, Effects of gas chromatography (GC) injector temperature on desorption of volatile organic compounds (VOCs) of Phytophthora cinnamomi + V8 juice agar and V8 juice agar alone from the 50/30 $\mathrm{mm}$ divinylbenzene/carboxen/polydimethylsiloxane (DVB/CAR/PDMS) fiber after $16 \mathrm{~h}$ of extraction; B, effects of desorption time on desorption of VOCs of $P$. cinnamomi + V8 juice agar and V8 juice agar alone from the 50/30 $\mu \mathrm{m}$ DVB/CAR/PDMS fiber. Bars represent standard errors of mean $(n=3)$. 
Analysis of six Phytophthora spp. and one Pythium sp. The optimized HS-SPME and GC conditions were applied to detect the VOCs of the six Phytophthora spp. and one Pythium sp. The GC chromatograms were different between the six Phytophthora spp., although one or two of the same retention time peaks (a, b, c, d, f, and g) were present in each species. Phytophthora spp. belonging to the same clade (P. niederhauserii and $P$. cinnamomi, clade $7 ; P$. multivora and $P$. elongata, clade $2 ; P$. inundata and $P$. humicola, clade 6) had different chromatograph patterns. The GC chromatogram patterns were also different between Pythium dissotocum and the six Phytophthora spp. (Fig. 5), with peak e only present in $P$. dissotocum and, except for peak b, no further specific peaks common to $P$. dissotocum were observed.

The optimized HS-SPME and GC conditions were also used to detect the VOCs from the five Phytophthora cinnamomi isolates. The results showed that all five $P$. cinnamomi isolates had the same GC chromatogram patterns when grown on V8A or PDA (Fig. 6). The VOCs from P. cinnamomi MP94.48 had the same GC chroma- togram patterns when it was grown on different substrates, except for two additional peaks ( $\mathrm{a}$ and $\mathrm{b}$ ), when P. cinnamomi was inoculated into lupin seedlings growing in sand or in the absence of sand (Fig. 7).

LOD. The LODs of the four external standards were evaluated under the optimal experimental conditions in a range of concentrations from 0 (control) to $300 \mathrm{ng} /$ liter ( 0 to 176.4 parts per billion) that separated on the polar column. The GC response for the four standards increased with concomitant increase in the concentrations of the standards and there were significant (regression coefficient > 0.989) linear regressions for all four standards (Fig. 8; Table 2). The LODs were calculated by comparing the signal-tonoise ratio $(\mathrm{S} / \mathrm{N})$ of the lowest concentration to $\mathrm{S} / \mathrm{N}=3$. The method allows detection of the external standards at concentrations lower than $43.08 \mathrm{ng} / \mathrm{liter}$, and the four standards had good separation on the polar column (Table 3).

In order to fully validate the HS-SPME-based procedure, its performance was compared with that of the conventional HS syringe

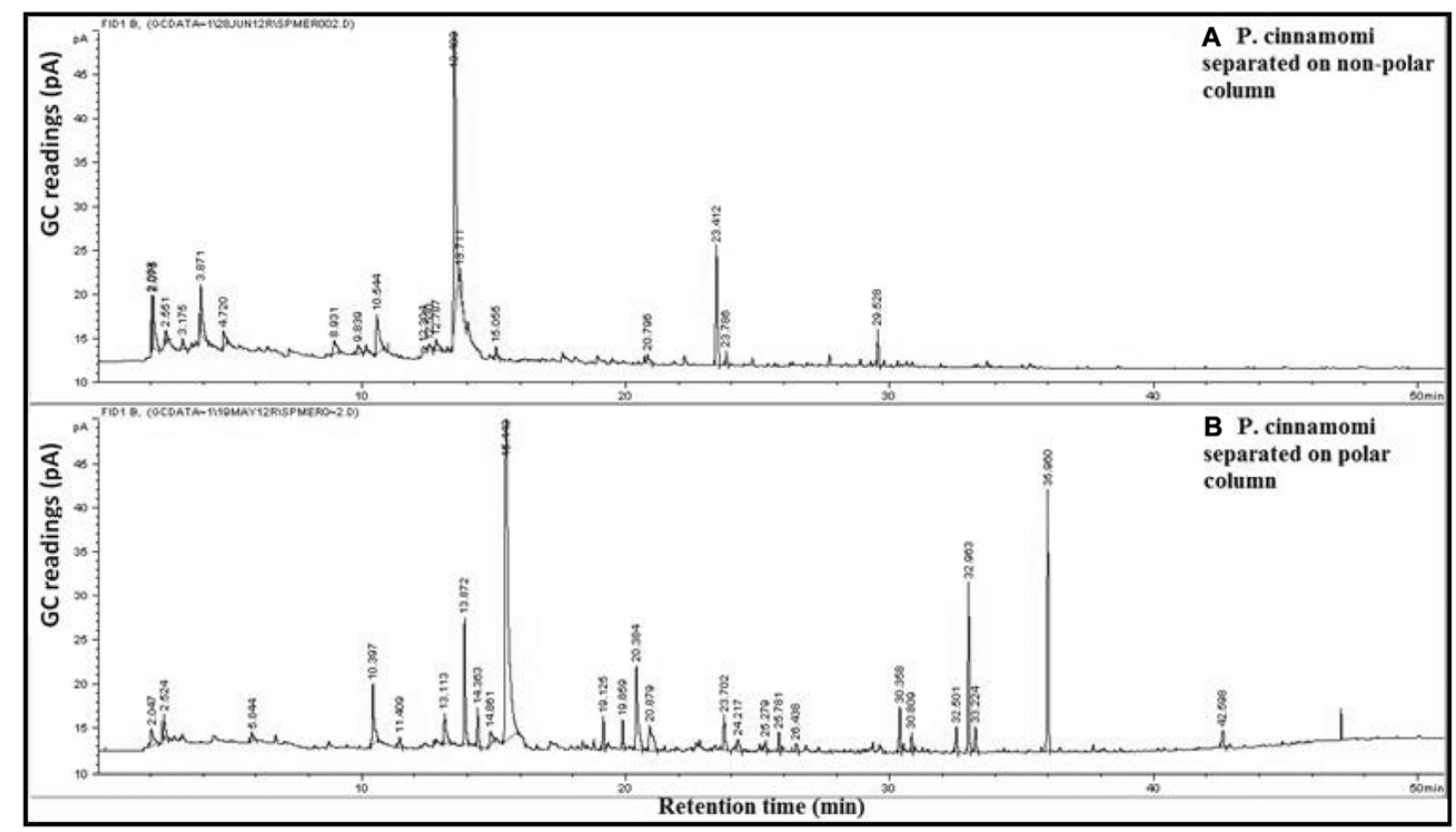

Fig. 4. Gas chromatography (GC) of a 6-day old Phytophthora cinnamomi + V8 juice agar that was separated on A, Rxi-5ms nonpolar column and B, ZB-WAX plus polar column.

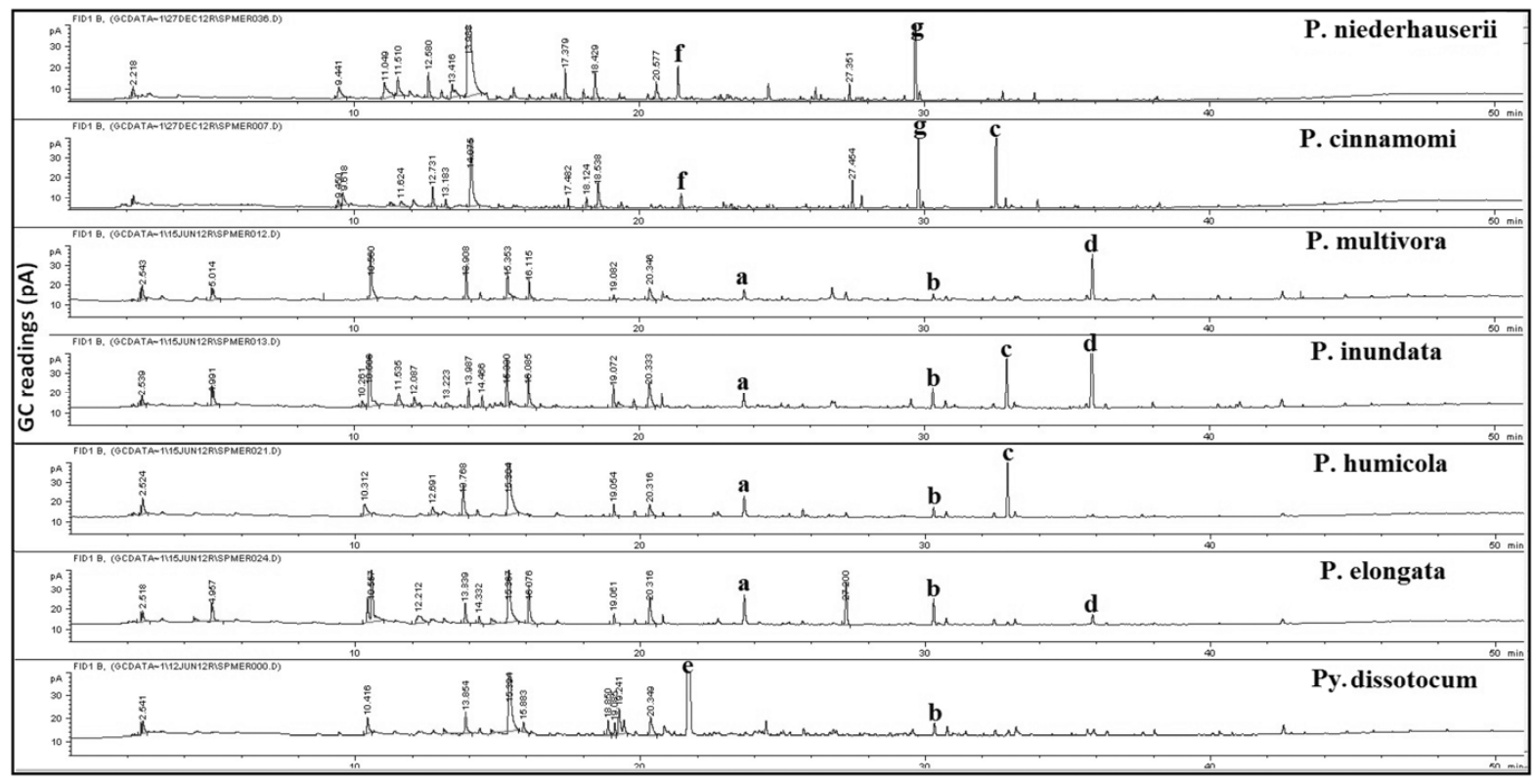

Fig. 5. Gas chromatography (GC) chromatograms of five different Phytophthora spp. and one Pythium sp. grow on V8 juice agar. 
procedure. Ethyl formate can be detected at less than 475 parts per trillion with the HS-SPME method, whereas concentrations at 3 ppm were not detected by conventional HS chromatography, which is $0.63 \times 10^{4}$ times less sensitive than the concentrations detected by the HS-SPME method.

The precision of the method was obtained by analyzing the VOCs from five replicate flasks each of $P$. cinnamomi + V8A and V8A. The retention time fluctuation of all the VOCs of interest with relative standard deviation values were between 0.852 and $9.010 \%$ for P. cinnamomi + V8A and between 0.671 and $1.912 \%$ for V8A.

The GC chromatograms and morphology observation. The VOCs from $P$. cinnamomi that were grown on V8A were detected under the optimized HS-SPME and GC conditions: in comparison with the control (V8A alone), compounds 1, 2, 3, 4, 7, and 9 were lost; compound 8 was dramatically reduced; and compound 6 was increased. However, compounds 5, 11, and 12 were present during all growth stages of $P$. cinnamomi, whereas compound 13 was observed only when hyphae were present and was lost when chlamydospores were produced, and compound 10 was only produced with the formation of chlamydospores (Fig. 9). According to the separation principle that the longer the retention time, the larger the molecular weight, we can conclude that the VOCs of $P$. cinnamomi were large molecular weight compounds.

Detection of $\boldsymbol{P}$. cinnamomi from naturally infested soil samples. The HS-SPME GC method resulted in $100 \%$ identification from the 15 naturally infested forest soil samples (Table 4); 3 and 13 samples using the HS-SPME GC directly from the soil and the baits, respectively, were $P$. cinnamomi positive and none of the baiting water samples were $P$. cinnamomi positive. When the baits were plated onto the selective agar, 13 soil samples were positive.

\section{Discussion}

The bipolar three-phase fiber 50/30 $\mu \mathrm{m}$ DVB/CAR/PDMS had the highest efficiency as an absorbent to extract VOCs in the HS over an actively growing colony of $P$. cinnamomi under separation with both polar and nonpolar GC columns. This efficiency was followed by the CAR/PDMS, PDMS/DVB, and PA fibers, and no compounds were detected with the PDMS fibers (except for two compounds detected by the $100 \mu \mathrm{m}$ PDMS fiber when separated on
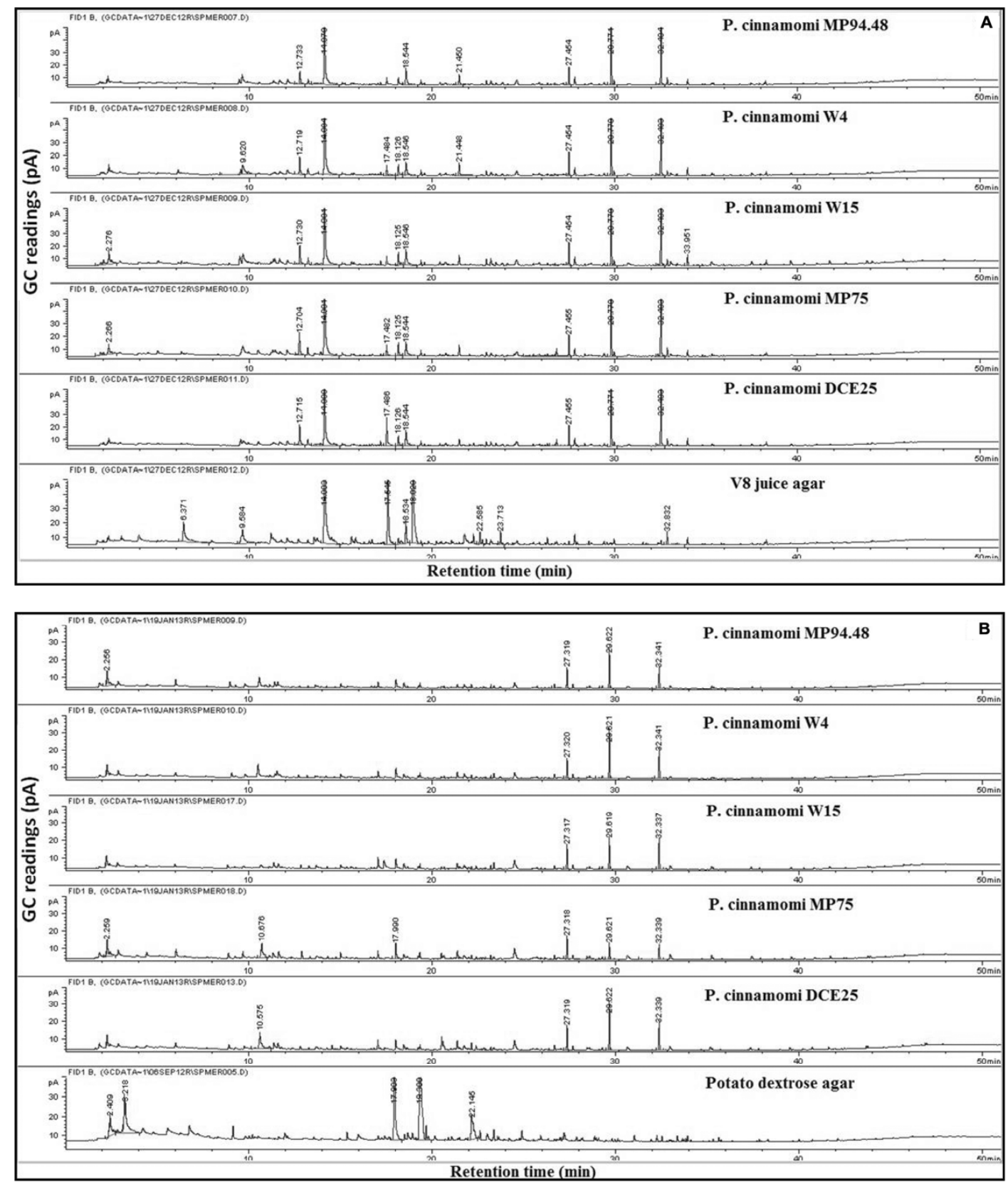

Fig. 6. Gas chromatography (GC) chromatograms of five Phytophthora cinnamomi isolates grown on A, V8 juice agar and B, potato dextrose agar. 
a nonpolar column). This result indicates that the volatile metabolites produced by $P$. cinnamomi are mainly polar compounds. These are consistent with the specified characteristics of the fibers; for example, the CAR/PDMS coated fiber is the best for extracting small analytes, the PDMS/DVB is suitable for more volatile polar molecules, the PA fiber is suitable for the extraction of very polar and large-sized analytes, and the three-phase bipolar fiber is suitable for a broad range of volatile and semivolatile analytes of $\mathrm{C}_{2}$ to $\mathrm{C}_{20}$. Therefore, we can conclude that the VOCs released by P. cinnamomi are polar volatile compounds.

Increasing the sample temperature can increase the HS capacity or analyte partitioning coefficient between air and solid phases, which leads to an increase in the total mass extraction or the rate of mass transfer onto the fiber coating, shortened equilibration times, and a faster overall SPME procedure (24). However, raising the sample temperature further can decrease the analyte distribution constant between the sample matrix and the fiber coating and decrease the sensitivity and recovery of the method (22). The optimal temperature for $P$. cinnamomi growth is 24 to $28^{\circ} \mathrm{C}$; lower or higher temperatures will reduce the activity of $P$. cinnamomi
$(14,27)$ and, in turn, could limit the release of VOCs. Consequently, in this study, we only used the optimal growth temperature $24 \pm 1{ }^{\circ} \mathrm{C}$. Also, in this study, optimal fiber extraction was $16 \mathrm{~h}$, which is quite a long time in comparison with Barbieri et al. (3), who reported $10 \mathrm{~min}$ as the extraction time necessary to reach equilibrium for compounds produced by Staphylococcus pasteuri. This is because the HS-SPME technique is a dynamic equilibrium process. The extraction time depends on the distribution constant, chemical nature of the desired compounds, and fiber polymeric phase, and analytes with bigger molecular mass (e.g., sterols and polyunsaturated fatty acids) are expected to need longer equilibrium times due to their lower partitioning and diffusion coefficient. Moreover, a 5-min desorption time was needed to completely remove the absorbed VOCs from the fiber, which indicated that some VOCs are bigger molecular volatility compounds and agrees with Grant's findings that the metabolic compounds of Phytophthora spp. are characterized by large unsaturated compounds (13).

Desorption is an endothermic process and is disfavored at low temperatures; theoretically, desorption temperature should be high enough to completely release absorbed volatiles from the fiber.

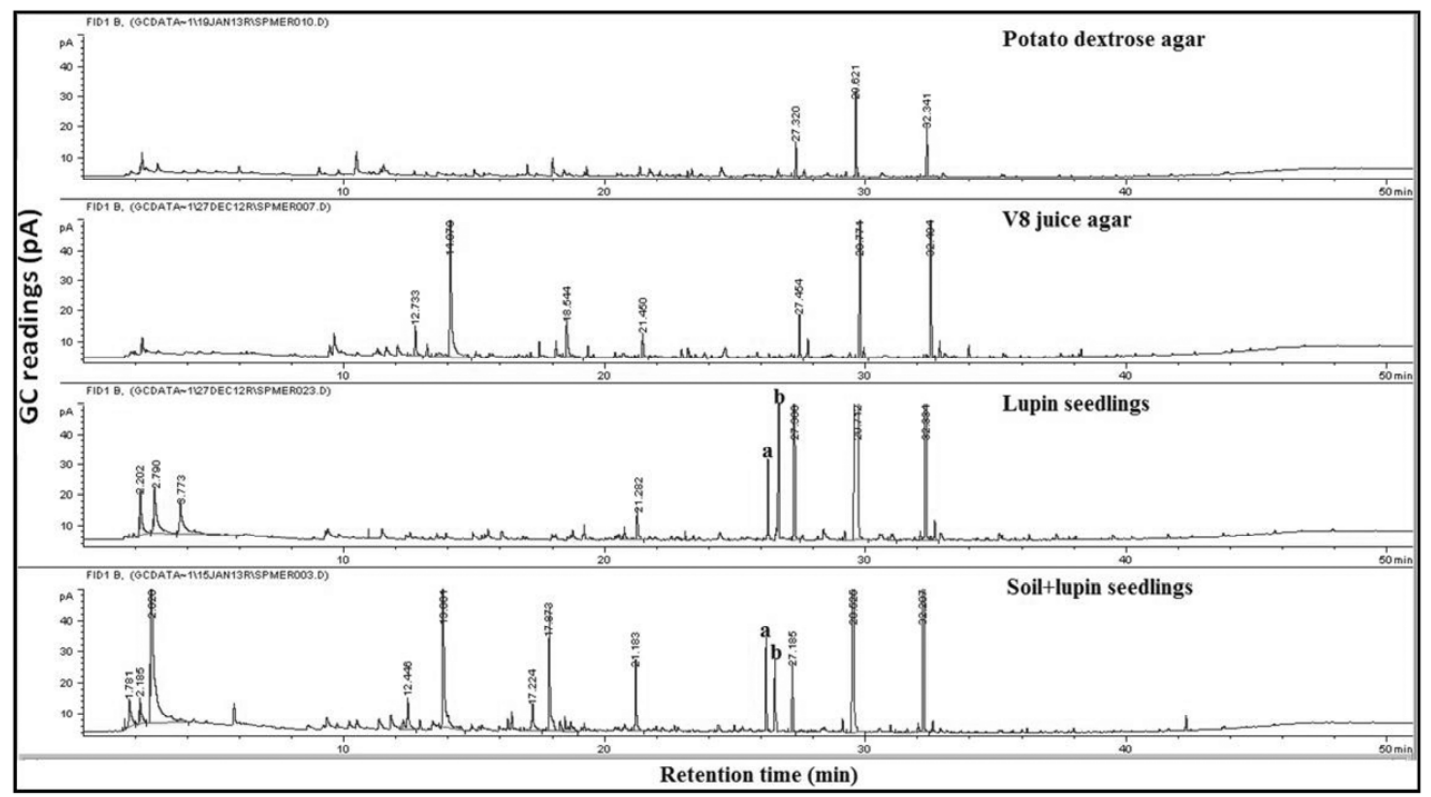

Fig. 7. Gas chromatography (GC) chromatograms of Phytophthora cinnamomi grow on different substrates.

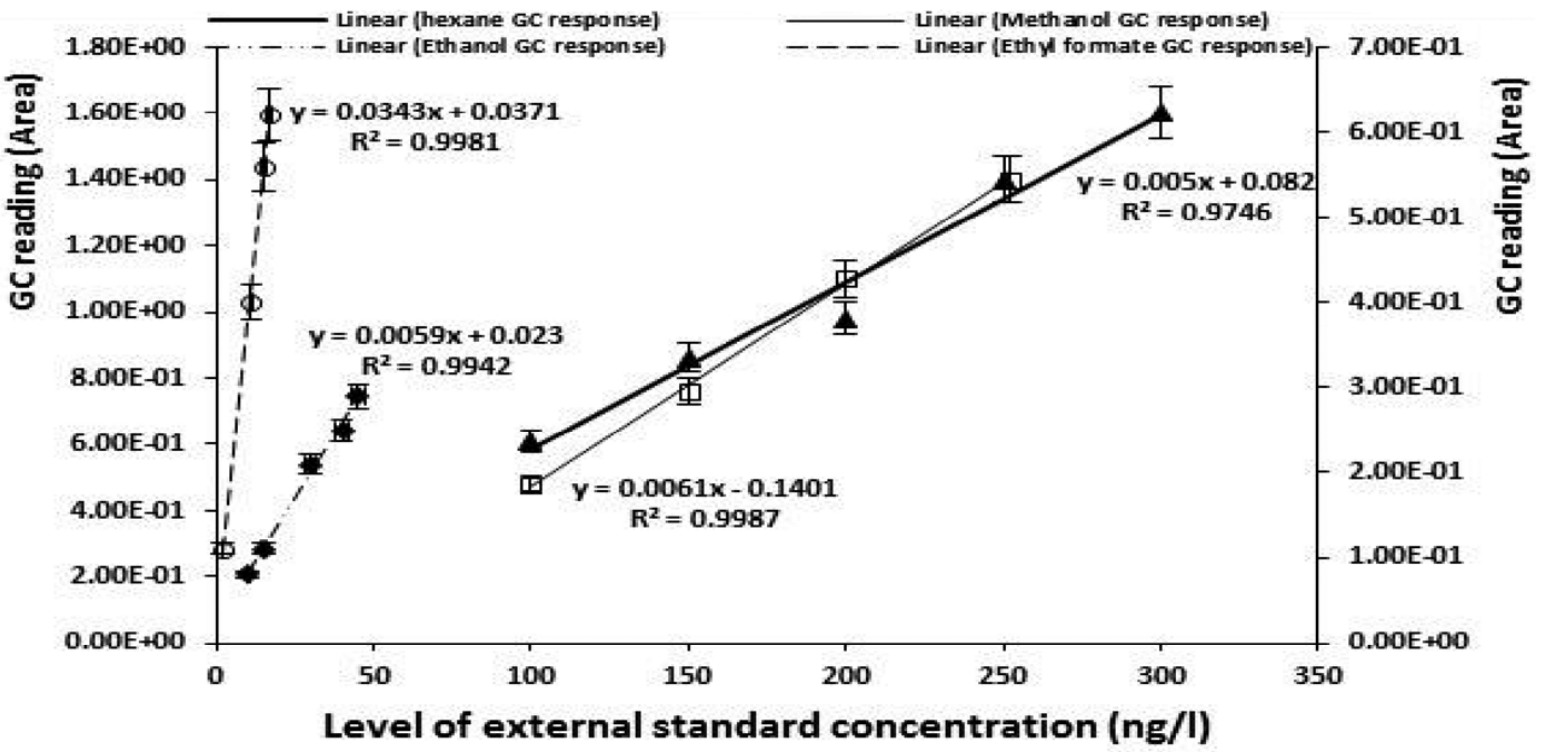

Fig. 8. Linearity of four external standards separated on the polar column; right $Y$-axis is for solid lines and the left $Y$-axis is for dashed lines. 
However, two factors should be considered: (i) in the SPME technique, only those injector temperatures that are within the temperature stability range of a particular fiber coating should be tested (e.g. for the three-phase fiber, $270^{\circ} \mathrm{C}$ is recommended as the limit of temperature tolerance) and (ii) the higher desorption temperature can reduce GC sensitivity; this could be due to denaturization, destruction, or decomposition of the chemicals at higher temperature. Also, the application of very high temperatures can shorten the fiber's life and result in loss of fiber polymer. Because the optimum desorption efficiency was achieved at $250^{\circ} \mathrm{C}$, this temperature was selected for the subsequent experiments.

Using the optimized HS-SPME method developed in this study, we found that the GC chromatogram of $P$. cinnamomi differed from the other Phytophthora spp. and Pythium dissotocum, and even the chromatogram patterns of species in the same clade were different. The closer the genetic distance of Phytophthora cinnamomi to other Phytophthora spp., the more similar were the GC chromatogram patterns. The chromatograms of different isolates of $P$. cinnamomi were the same. Using different growth media did not confound the VOCs that were released by $P$. cinnamomi, although two additional peaks were evident when $P$. cinnamomi infected and colonized lupin seedlings (grown in sand or in the absence of sand); this may be due to more adequate nutrition from these substrates resulting in larger concentrations of VOCs. The concentration of these two VOCs was below the detection limit when P. cinnamomi was grown on V8A and PDA. However, the majority of the peaks were consistent across the different substrates on which $P$. cinnamomi was grown. The results clearly demonstrated that the HS-SPME combined with GC coupled to FID can be reliably used to analyze VOCs for the specific identification of P. cinnamomi and that other Phytophthora spp. produced different VOCs, although the methods could not differentiate between the different isolates of $P$. cinnamomi. This indicates that the method appears to be $P$. cinnamomi specific. The quantity of $P$. cinnamomi in soil is very small (33), and the soil samples used in this study were collected in November, when the weather is very dry and hot, conditions that are not generally conducive for $P$. cinnamomi activity. Conse-

Table 4. Gas chromatography coupled to a flame ionization detector (GCFID) detection of Phytophthora cinnamomi from fresh soil samples and baits

\begin{tabular}{lcccc}
\hline & \multicolumn{3}{c}{ GC-FID detection } & \\
\cline { 2 - 4 } Soil sample & Soil & Water & Baits & Baits plating $(\%)^{\mathbf{b}}$ \\
\hline 716 & - & - & + & 71 \\
717 & - & - & + & 66 \\
722 & - & - & + & 80 \\
T2+4 & - & - & + & 97 \\
T2+6 & - & - & + & 89 \\
T3+4 & - & - & + & 100 \\
T3+6 & - & - & + & 100 \\
T3+8 & - & - & + & 100 \\
T6+4 & - & - & + & 77 \\
MU22-1 & - & - & + & 47 \\
MU22-2 & + & - & + & 44 \\
MU22-3 & - & - & + & 71 \\
MU22-4 & + & - & - & 0 \\
MU22-5 & - & - & + & 68 \\
MU04 & + & - & - & 0 \\
\hline
\end{tabular}

${ }^{\mathrm{a}}$ Soil $=$ fresh soil sample, Water $=$ baiting water, + indicates positive detection, and - indicates not detected.

${ }^{\mathrm{b}}$ Percent baiting efficiency $(\%)=($ baits yielding $P$. cinnamomi/total baits exposed) $\times 100$.

Table 3. Analyzed external standards, limits of detection (LOD), and linearity data in gas chromatography coupled to a flame ionization detector by using $50 / 30 \mu \mathrm{m}$ divinylbenzene/carboxen/polydimethylsiloxane fiber

\begin{tabular}{lccccc}
\hline Standards & RT $(\mathbf{m i n})^{\mathbf{a}}$ & Linearity $\left(\boldsymbol{r}^{\mathbf{2}} \mathbf{b}^{\mathbf{b}}\right.$ & LOD (ng/liter) & LOD (ppb) & Molecular number $^{\mathbf{c}}$ \\
\hline Methanol & 5.929 & 0.993 & 27.36 & 19.15 & $1.287 \times 10^{14}$ \\
Ethanol & 6.766 & 0.989 & 5.29 & 2.58 & $1.731 \times 10^{13}$ \\
Ethyl formate & 4.734 & 0.995 & 4.57 & 0.47 & $3.191 \times 10^{12}$ \\
Hexane & 1.642 & 0.988 & 43.08 & 11.20 & $7.526 \times 10^{13}$ \\
\hline
\end{tabular}

${ }^{\mathrm{a}} \mathrm{RT}=$ retention time.

${ }^{\mathrm{b}}$ Regression coefficient.

${ }^{\mathrm{c}}$ In parts per billion (ppb)

${ }^{\mathrm{d}}$ For all standards, $1 \mathrm{~mol}$ molecular number $=6.022 \times 10^{23}$.

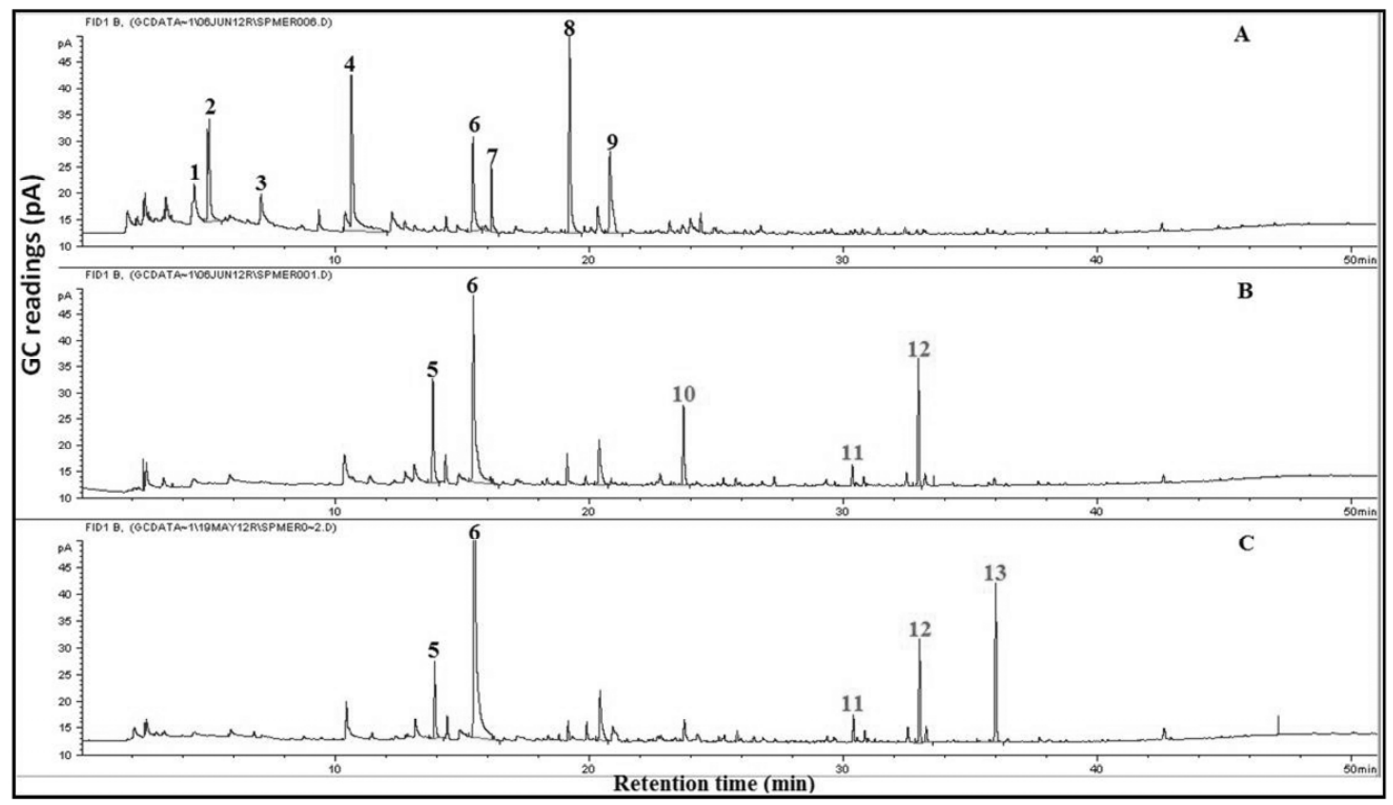

Fig. 9. Chromatograms of A, V8 juice agar alone and Phytophthora cinnamomi at different stages of growth on V8 juice agar: B, chlamydospores and C, hyphae. 
quently, under these conditions, $P$. cinnamomi will likely be dormant in the soil, resulting in limited detection of VOCs due to a lower metabolic rate of $P$. cinnamomi. After flooding, $P$. cinnamomi will produce sporangia and release zoospores which, in turn, infect and colonize the baits, resulting in the release of concentrated specific VOCs, beneficial for HS-SPME GC analysis. These life cycle traits could be the reason for low identification efficiency from the fresh but dry soil samples, and for the high identification efficiency from the baits by HS-SPME GC analysis. Although $P$. cinnamomi was isolated by directly plating root material from the naturally infested soil samples MU22-4 and MU04, the baiting results were negative but HS-SPME GC results were positive. The sensitivity of baits to different $P$. cinnamomi isolates has been shown to differ (1); consequently, this could be a potential reason for the negative result from the baits; alternatively, these soils contained microorganisms that suppressed sporangial production or zoospore release. All these results proved the feasibility and sensitivity of HS-SPME GC method for the detection of P. cinnamomi from different substrates.

The efficiency and low background interference of GC/FID and its nondestructive nature allows the SPME fiber to be used repeatedly. In addition, with the method developed in this study, VOCs can be detected at levels lower than $19.15 \mathrm{ppb}$, which demonstrates that this method can be used to identify and determine P. cinnamomi-specific VOCs at very low levels.

The loss or decrease of smaller compounds from V8A and the massive increase or emergence of larger compounds from $P$. cinnamomi samples may have resulted from an increase in the metabolism of $P$. cinnamomi between the mycelial and sporangial stages. Also, different VOCs were released from $P$. cinnamomi during its different growth stages; these results are in accordance with other researchers' opinions on physiological metabolism $(13,34)$. We believe that study of metabolite profiles at the various stages of development of $P$. cinnamomi may provide important clues as to the major metabolic pathways that operate during its different growth stages. Therefore, the optimized method developed in this study can be used either as a detection tool or as a new qualitative methodology for physiological studies of $P$. cinnamomi and other oomycetes.

SPME is a simple preparation technique that can be used both in laboratory and on-site (35). HS-SPME can shorten the time of extraction significantly because of the faster diffusion rate of the molecules in the gaseous phase. Because the fiber is suspended in the HS above the sample layer, there is no contamination of the fiber by the sample. From our studies, it is observed that the fibers can be reused more than 200 times, thus reducing the cost of the materials. The HS-SPME GC technique does not require a great deal of skill and can be readily used after a short period of training.

To our knowledge, this is the first use of VOCs as an indicator of $P$. cinnamomi colonization and infection and it is the first time the HS-SPME technique has been used to identify VOCs of $P$. cinnamomi. This study had shown that HS-SPME GC is a robust and costeffective system for the diagnosis of $P$. cinnamomi based on the production of specific VOCs, and studies are in progress to characterize and identify the VOCs that are released by $P$. cinnamomi to eventually develop an efficient control method for $P$. cinnamomi. Currently, we are using this method to characterize the VOC's from P. cinnamomi and other Phytophthora spp. by GC/MS.

\section{Acknowledgments}

We thank the China Scholarship Council and CRC Plant for National Biosecurity for their financial support; the Centre for Phytophthora Science and Management, Murdoch University, Australia for their support in supplying the Phytophthora isolates; C. Rawlinson from the Separation Science Laboratory and B. Dunstan, T. Paap, D. White, S. Aghighi, and A. Simamora from the Centre for Phytophthora Science and Management for their technical support; and Murdoch University, Australia for providing laboratory space and facilities to $\mathrm{R}$. Qiu.

\section{Literature Cited}

1. Anderson, E. J. 1951. A simple method for detecting the presence of Phytophthora cinnamomi Rands in soil. Phytopathology 41:187-188.
2. Arthur, C. L., and Pawliszyn. J. 1990. Solid phase microextraction with thermal, desorption using fused silica optical fibers. Anal. Chem. 62:21452148 .

3. Barbieri, E., Cioacchini, A. M., Zambonelli, A., Bertini, L., and Stocchi, V. 2005. Determination of microbial volatile organic compounds from Staphylococcus pasteuri against Tuber borchii using solid-phase microextraction and gas chromatography/ion trap mass spectrometry. Rapid Commun. Mass Spectrom. 19:3411-3415.

4. Cahill, D. M., Rookes, J. E., Wilson, B. A., Gibson, L., and McDougall, K. L. 2008. Turner Review No. 17. Phytophthora cinnamomi and Australia's biodiversity: Impacts, predictions and progress towards control. Aust. J. Bot. 56:279-310.

5. Cooke, D. E. L., Duncan, J. M., Williams, N. A., Hagenaar-de Weerdt, M., and Bonants, P. J. M. 2001. Identification of Phytophthora species on the basis of restriction enzyme fragment analysis of the internal transcribed spacer regions of the ribosomal RNA. EPPO Bull. 30:519-523.

6. Cooke, D. E. L., Schena, L., and Cacciola, S. O. 2007. Tools to detect, identify and monitor Phytophthora species in natural ecosystems. J. Plant Pathol. 89:13-28.

7. De Lacy Costello, B. P. J., Evans, P., Ewen, R. J., Gunson, H. E., Jones, P. R. H., Ratcliffe, N. M., and Spencer-Phillips, P. T. N. 2001. Gas chromatography-mass spectrometry analyses of volatile organic compounds from potato tubers inoculated with Phytophthora infestans or Fusarium coeruleum. Plant Pathol. 50:489-496.

8. Duan, C. H., Riley, M. B., and Jeffers, S. N. 2008. Characterization of Phytophthora cinnamomi populations from ornamental plants in South Carolina, USA. Arch. Phytopathol. Plant Prot. 41:14-30.

9. Dunstan, W. A., Rudman, T., Shearer, B. L., Moore, N. A., Paap, T., Calver, M. C., Dell, B., and Hardy, G. E. St. J. 2010. Containment and spot eradication of a highly destructive, invasive plant pathogen (Phytophthora cinnamomi $)$ in natural ecosystems. Biol. Invas. 12:913-925.

10. Erwin, D. C., and Ribeiro, O. K. 1996. Phytophthora Diseases Worldwide. American Phytopathological Society, St. Paul, MN

11. Espy, M. J., Uhl, J. R., Sloan, L. M., Buck-Walter, S. P., Jones, M. F., Vetter, E. A., Yao, J. D. C., Wengenack, N. L., Rosenblatt, J. E., Cockerill, F. R., and Smith, T. F. 2006. Real-time PCR in clinical microbiology application testing. Clin. Microbiol. Rev. 19:165-256.

12. Garkaklis, M. J., Calver, M. C., Wilson, B. A., and Hardy, G. E. St. J. 2004 Habitat alteration caused by introduced plant disease: a significant threat to the conservation of Australian forest fauna. Pages 899-913 in: Conservation of Australia's Forest Fauna. D. Lunney, ed. Royal Zoological Society of New South Wales, Mosman, New South Wales, Australia.

13. Grant, B. R., Greenaway, W., and Whatley, F. R. 1988. Metabolic changes during development of Phytophthora palmivora examined by gas chromatography/mass spectrometry. J. Gen. Microbiol. 134:1901-1911.

14. Halsall, D. M., and Williams, J. D. 1984. Effect of root temperature on the development of Phytophthora cinnamomi root rot in Eucalyptus seedlings. Aust. J. Bot. 32:521-528.

15. Hardham, A. R. 2005. Pathogen profile Phytophthora cinnamomi. Mol Plant Pathol. 6:589-604

16. Hüberli, D., Tommerup, I. C., and Hardy, G. E. St. J. 2000. False-negative isolations or absence of lesions may cause mis-diagnosis of diseased plant infected with Phytophthora cinnamomi. Aust. Plant Pathol. 29:164-169.

17. Ibrahim, A.D., Abubakar, A., Aliero, A. A., Sani, A., and Yakubu, S. E. 2011. Volatile metabolites profiling for discriminating tomato fruits inoculated with some bacterial pathogens. J. Pharm. Biomed. Sci. 1:79-84

18. Ippolito, A., Schena, L., Soleti Ligorio, V., Yaseen, T., and Nigro, F. 2004 Real time detection of Phytophthora nicotianae and P. citrophthora in citrus roots and soils. Eur. J. Plant Pathol. 110:833-843.

19. Laothawornkitkul, J., Jansen, R. M. C., Smid, H. M., Bouwmeester, H. J. Muller, J., and van Bruggen, A. H. C. 2010. Volatile organic compounds as a diagnostic marker of late blight infected potato plants: a pilot study. Crop Prot. 29:872-878

20. Linde, C., Drenth, A., and Wingfield, M. J. 1999. Gene and genotypic diversity of Phytophthora cinnamomi in South Africa and Australia revealed by DNA polymorphisms. Eur. J. Plant Pathol. 105:667-680.

21. Linde, C., Kemp, G. H. J., and Wingfield, M. J. 1999. Variation in pathogenicity among South African isolates of Phytophthora cinnamomi. Eur. J. Plant Pathol. 105:231-239.

22. Magan, N., and Evans, P. 2000. Volatiles as an indicator of fungal activity and differentiation between species, and the potential use of electronic nose technology for early detection of grain spoilage. J. Stored Prod. Res. 36:319-340.

23. McNeal, K. S., and Herbert, B. E. 2009. Volatile organic metabolites as indicators of microbial activity and community composition shifts. Soil Sci. Am. J. 73:579-588

24. Risticevic, S., Lord, H., Górecki, T., Arthur, L., and Pawliszyn, J. 2010. Protocol for solid-phase microextraction method development. Nat. Protocols 5:122-139.

25. Schnürer, J., Olason, J., and Börjesson, T. 1999. Fungal volatiles as indicators of food and feeds spoilage. Fungal Genet. Biol. J. 27:209-217.

26. Shea, S. R., Shearer, B. L., Tippett, J. T., and Deegan, P. M. 1983. Distribution, reproduction, and movement of Phytophthora cinnamomi on sites highly conducive to jarrah dieback in south Western Australia. Plant Dis. 
67:970-973.

27. Shew, H. D., and Benson, D. M. 1983. Influence of soil temperature and inoculums density of Phytophthora cinnamomi on root rot of Fraser fir. Plant Dis. 67:522-524.

28. Tooley, P. W., Martin, F. N., Carras, M. M., and Frederick, R. D. 2006. Real-time fluorescent polymerase chain reaction detection of Phytophthora ramorum and Phytophthora pseudosyringae using mitochondrial gene regions. Phytopathology 96:336-345.

29. Vettraino, A. M., Barzanti, G. P., Bianco, M. C., Ragazzi, A., Capretti, P., Paoletti, E., Luisi, N., Anselmi, N., and Tannini, A. 2002. Occurrence of Phytophthora species in oak stands in Italy and their association with declining oak trees. For. Pathol. 32:19-28.

30. Vettraino, A. M., Bonants, P., Tomassini, A., Bruni, N., and Vannini, A. 2012. Pyrosequencing as a tool for detection of Phytophthora species: error rate and risk of false MOTUs. Lett. Appl. Microbiol. 55:390-396.

31. Vettraino, A. M., Morel, O., Perlerou, C., Robin, C., Diamandis, S., and Vannini, A. 2005. Occurrence and distribution of Phytophthora species in European chestnut stands, and their association with Ink Disease and crown decline. Eur. J. Plant Pathol. 111:169-180.

32. Wilson, B. A., Newell, G., Laidlaw, W. S., and Friend, G. 1994. Impact of plant diseases on faunal communities. J. R. Soc. West Aust. 77:139-143.

33. Zentmyer, G. A. 1980. Phytophthora cinnamomi and the diseases it causes. Monogr. No. 10, American Phytopathological Society, St. Paul MN.

34. Zhu, J. J., Bean, H. D., Kuo, Y. M., and Hill, J. E. 2010. Fast detection of volatile organic compounds from bacterial cultures by secondary electrospray ionization-mass spectrometry. J. Clin. Microbiol. 48:4426-4431.

35. Zhu, J. Y., and Chai, X. S. 2005. Some recent developments in headspace gas chromatography. Curr. Anal. Chem. 1:79-83. 